\title{
Perinatal Regionalization and Implications for Long-Term Health Outcomes in Cerebral Palsy
}

\author{
Corneliu Bolbocean, Pia Wintermark, Michael I. Shevell, Maryam Oskoui MD
}

\begin{abstract}
Background: Perinatal regionalization is linked to improved neonatal outcomes; however, the effects on long-term outcomes in cerebral palsy (CP) are not known. We estimate the effect of highest levels of neonatal care available at delivery on the risk of developing a nonambulatory CP status. Methods: Children with CP born in Quebec from the Canadian CP Registry excluding postneonatal causes were included $(\mathrm{N}=360)$. We estimate the effect of level of care available at delivery on risk of nonambulatory status among children with $\mathrm{CP}$ using propensity score matching and instrumental variables methods to adjust for differences in case mix among the three groups of hospitals. The outcome variable is an indicator for CP nonambulation assigned according to Gross Motor Function Classification System (levels IV and V). This study used data that predated therapeutic hypothermia in Quebec. Results: Propensity score estimates of change in the adjusted risk of having a nonambulatory CP status because of birth at level II versus level I is $-0.081,95 \%$ confidence interval (CI; -0.2182 to 0.0562$)$; level III versus level I is $-0.07295 \%$ CI ( -0.225 to 0.08$)$, and level III versus level II is $0.15795 \%$ CI (0.027 to 0.286). Conclusions: Differences in levels of neonatal care available at hospital where the delivery was carried out are not associated with the risk of a nonambulatory CP phenotype. This suggests that level of care and associated medical technology within the Quebec regionalized neonatal-perinatal system is used efficiently because it does not offer any further marginal benefit in the reduction of severe CP outcomes. The system works well as it is, which is supportive of the perinatal regionalization. The success of the neonatal resuscitation program and referral of high-risk births to regional hospitals with sufficient obstetric and perinatal competence and resources may contribute to this lack of variability.
\end{abstract}

RÉSUMÉ: Régionalisation des soins périnataux et répercussions à long terme sur la santé dans la paralysie cérébrale. Contexte: Il existe un lien entre la régionalisation des soins périnataux et une amélioration de la santé néonatale. Cependant, les effets à long-terme sur la santé dans la paralysie cérébrale (PC) ne sont pas connus. Nous avons estimé l'effet des plus hauts niveaux de soins néonataux disponibles au moment de l'accouchement sur le risque de PC non ambulatoire. Méthode: Les enfants atteints de PC nés au Québec et identifiés dans le Registre canadien de paralysie cérébrale, excluant les causes postnéonatales de PC, ont été inclus dans l'étude $(\mathrm{N}=360$. Nous avons estimé l'effet du niveau de soins disponible au moment de l'accouchement sur le risque de PC non ambulatoire chez ces enfants au moyen de la méthode d'appariement des coefficients de propension et de la méthode des variables instrumentales pour tenir compte des différences entre les types de cas traités dans trois groupes d'hôpitaux. La variable dépendante était un indicateur de la PC non ambulatoire assignée selon le Gross Motor Function Classification System (niveaux IV et V). Cette étude porte sur des données antérieures à l'utilisation de l'hypothermie thérapeutique au Québec. Résultats: Les estimés des coefficients de propension de modification du risque ajusté de présenter une PC non ambulatoire parce que la naissance a eu lieu dans une institution à niveau de soins II par rapport à une institution à niveau de soins I est de $-0,081$ (intervalle de confiance [IC] à $95 \%$ : $-0,2182$ à 0,0562 ), dans une institution à niveau de soins III par rapport une institution à un niveau de soins I de $-0,072$ (IC à $95 \%$ : $-0,225$ à 0,08 ) et dans une institution à niveau de soins III par rapport à une institution à niveau de soins II de 0,157 (IC à 95\%:0,027 à 0,286). Conclusions: Les différences dans les niveaux de soins néonataux disponibles à l'hôpital où la naissance a eu lieu ne sont pas associées au risque de présenter un phénotype de PC non ambulatoire. Ceci suggère que le niveau de soins et la technologie médicale qui y est associée dans le système néonatal-périnatal régionalisé du Québec est utilisé avec efficience car il n'offre pas de bénéfice supplémentaire pour diminuer le nombre de cas de PC sévère. Le système fonctionne bien tel qu'il est, ce qui est en faveur de la régionalisation des soins périnataux. Il se peut que le succès du programme de réanimation néonatale et l'orientation des naissances à haut risque vers des hôpitaux régionaux ayant une compétence obstétricale et périnatale ainsi que des ressources suffisantes contribue à cette absence de variabilité.

Keywords: Cerebral palsy, neonatal

doi:10.1017/cjn.2015.322

Can J Neurol Sci. 2016; 43: 248-253

Perinatal regionalization, known as tiered provision of neonatal care, emerged over time as a strategy to provide optimal, risk-appropriate maternal child services for a geographically dispersed population. These systems of regional perinatal services are now common across North America and Europe and are linked to improved outcomes of high-risk infants born either preterm or

From the Robbins Institute for Health Policy and Leadership, Department of Economics, Baylor University, Waco, TX (CB); Department of Pediatrics, McGill University, Montreal, Quebec (PW, MS, MO); Department of Neurology and Neurosurgery, McGill University, Montreal, Quebec (MS, MO).

Received June 17, 2015. Final Revisions Submitted July 28, 2015.

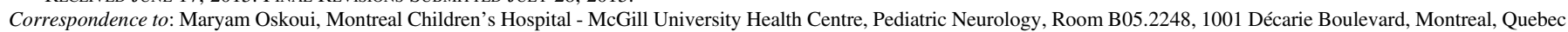
H4A 3J1. Email: maryam.oskoui@mcgill.ca 
with serious medical or surgical conditions. ${ }^{1,2}$ Following some initial recommendations, ${ }^{3}$ the Committee on Fetus and Newborn issued two policy statements on Levels of Neonatal Care. ${ }^{4,5}$ The 2012 policy statement recommended regionalized systems of perinatal care to ensure that each newborn infant is delivered and cared for in a facility most appropriate for his or her health care need. ${ }^{5}$

Existing evidence links perinatal regionalization with improved neonatal outcomes for the infants born preterm and with low birth weight. ${ }^{6}$ However, there are growing concerns about the high costs of neonatal intensive care as well as the substantial financial burden survivors of neonatal intensive care might pose to their families and the health care system. ${ }^{7,8}$ Although the overall efficacy of specific neonatal intensive care interventions has been established in the literature, ${ }^{9,10}$ limited evidence exists on the overall effectiveness of perinatal regionalization and its impact on long-term health outcomes.

This study evaluates the impact of perinatal regionalization on adverse long-term outcome based on data from the Canadian Multi-Regional Cerebral Palsy Registry (CCPR), which predated therapeutic hypothermia in Quebec. Our hypothesis was that the level of neonatal care available at the time of delivery may influence the risk of developing cerebral palsy $(\mathrm{CP})$ non-ambulatory status. We thus sought to evaluate the association between the level of neonatal care available at delivery and CP nonambulatory status.

\section{Materials ANd Methods}

The study was conducted using Quebec provincial data from the CCPR, which predated therapeutic hypothermia within the Quebec perinatal-neonatal system. The description of this unique registry can be found in Oskoui et al. ${ }^{11}$ Using the framework of the regionalization of pediatric rehabilitation service delivery, children with CP born in 1999 or after were enrolled within six of the province's 17 administrative health regions capturing approximately half of the province's population. Once cases are identified, parental consent is obtained and the maternal medical and obstetric records as well as the child's neonatal, medical, and rehabilitation records are reviewed. These data are supplemented by a standardized parental interview and physical examination of the child by a pediatric neurologist, developmental pediatrician, or child physiatrist. For each enrolled child, more than 120 variables are collected and entered into a Research Electronic Data Capture database. Local ethics board approval was obtained from each participating institution. The Montreal Children's HospitalMcGill University Health Center Research Institute ethics board provided central approval for data storage, analysis, and overall operations. To be enrolled in CCPR, a child must be at least 2 years of age and meet diagnostic criteria for $\mathrm{CP}$, which include clinical diagnosis of a nonprogressive motor impairment resulting from a presumably early insult to the developing brain. ${ }^{12}$ A follow-up at 5 years of age is used to confirm the diagnosis and update functional outcome variables.

Children within the CCPR included for analysis in this study were born between 1999 and 2008 in the province of Quebec, allowing all to have a 5-year follow-up and confirmation of status. Children with CP diagnosis linked to any identified postneonatal cause or cases born outside the province of Quebec were excluded from this analysis.

For the analysis, we classified children according to level of neonatal care available where delivery was carried out. ${ }^{5}$
In Quebec, maternity care is regionalized, and nearly all deliveries take place in public hospitals or birthing centers. Low-risk deliveries are carried out at level I hospitals (well newborn nurseries), level II hospitals (specialty care), or level III hospitals (subspecialty). We used clear, uniform definitions and consistent standards of level of neonatal care across Quebec, Canada, and appropriate adjustment for differences in case mix among the three groups of hospitals. We classified each delivery unit according to its level of neonatal care where delivery was carried out. ${ }^{5}$ This classification reflects differences in the level of obstetric and neonatal competences available at the hospital and is outlined in more detail in Appendix 1.

The outcome used for this analysis was CP nonambulatory status, as defined by a Gross Motor Function Classification System level IV and level V. ${ }^{13}$ The challenge of this research question was to control for case mix differences. In particular, level II and level III hospitals have a higher proportion of medium- and high-risk pregnancies compared with level I hospitals. We used a quasi-experimental study design (with nonequivalent comparison groups pretest-posttest), ${ }^{14}$ with controls for many relevant covariates to remove selection bias (bias by indication) that could originate from the differences in case mix among the three groups of hospitals. We used two standard methodologies to adjust for measured bias in these nonexperimental data. Methods included multivariate regression model risk adjustment and propensity-based matching. We first used multivariate linear regression, which allows for many risk factors to affect both referral to hospital type and outcome conditional on that referral. The multivariate linear regression model is the conventional modeling approach that incorporates all known confounders, including interactions, into the model. Controlling for these covariates produces a risk-adjusted treatment effect of the level of care and removes measured bias resulting from observed confounders. Second, we used propensity score matching, which is a specialized estimator that generally offers more precise estimates. However, we also used multivariate instrumental variable regression, which is a method designed to control for hidden bias in observational data. This technique allows for unobserved risk factors that affect the referral to hospital type and outcomes conditional on that referral, but which often suffers from imprecise estimates.

Our data contained a large number of variables about mother and child to make appropriate adjustments for differences in case mix between hospitals using propensity score matching. We used current clinical practice guidelines in obstetrics and gynecology, ${ }^{15}$ perinatal surveillance literature ${ }^{16}$ and CP risk factors ${ }^{17}$ to choose explanatory variables and make proper adjustments for differences in case mix between hospitals. The following covariates were used to control for risk factors (and deal with selection bias/ bias by indication): preeclampsia, gestational diabetes, bleeding during pregnancy, severe illness during pregnancy, accident or trauma during pregnancy, preterm birth, a family history of $\mathrm{CP}$, low maternal education (lacking a high school diploma), maternal age, history of drug use (We used current clinical practice guidelines in obstetrics and gynecology, ${ }^{15}$ perinatal surveillance literature, ${ }^{16}$ and $\mathrm{CP}$ risk factors ${ }^{17}$ to choose these control variables.). We also controlled for perinatal asphyxia, which was defined as neonatal encephalopathy with at least three of the following criteria: an Apgar score $<6$ at 5 minutes, a cord $\mathrm{pH}<7.0$, a cord base excess $>12$, an abnormal fetal heart rate such 
as tachycardia ( $>160$ beats per minute) or bradycardia $(<120$ beats per minute), presence of meconium, need for intubation, delay in spontaneous respiration, need for resuscitation of the newborn, multisystem involvement in the neonatal period, or abnormal imaging results consistent with hypoxic ischemic injury. We also tested for effect modification between perinatal asphyxia and level of care at delivery. However, the interaction variable was not statistically significant and postestimation tests suggested that it did not statistically significantly improve the model's performance. We subsequently did not include this interaction term.

\section{RESULTS}

Our cohort of 360 children with CP without any postneonatal cause was born in Quebec between 1999 and 2008. Forty-six percent were born in birth sites with level III neonatal care, $20 \%$ with level II, and the remainder (34\%) with level I neonatal care. Nonambulatory status (Gross Motor Function Classification System levels IV and V) was reported in 27\%. The other characteristics of the population are presented in Table 1.

Propensity score matching estimates, standard errors and associated $95 \%$ confidence intervals are displayed in Table 2 . These estimates measure risk-adjusted change in the probability of nonambulatory CP status because of increased level of service at delivery. Propensity score matching generally pointed to no effect relationship between the level of neonatal care at delivery where birth was carried out and later CP nonambulatory status. There was no statistical evidence that delivery carried out in levels II or III hospitals versus level I hospital has any effect on the incidence of $\mathrm{CP}$ nonambulatory status. We found risk estimates for level II versus level I and level III versus level I be weakly negative and not statistically significant. A positive and statistically significant risk estimate was found for the level III versus level II comparison. However, the propensity score matching substantially reduced the case mix differences between the groups of hospitals as absolute standardized bias after adjustments was $<5 \%$ for most risk factors. Our instrumental variables methods estimation confirmed no effect relationship between the level of care available at time of delivery and the $\mathrm{CP}$ nonambulatory status (Appendixes 3-5). Endogenous bivariate probit estimates identified no effect relationship with highest precision. We found that $\mathrm{CP}$ nonambulatory status was not affected by the type of hospital where delivery was carried out across propensity score matching and instrumental variables methods.

Linear probability model did show that several point estimates were statistically significant at conventional levels and are noteworthy (Table 3). These models found a statistically significant association between $\mathrm{CP}$ nonambulatory status and perinatal asphyxia $(\mathrm{p}<0.01)$, low maternal education $(\mathrm{p}<0.1)$, and preterm birth $(\mathrm{p}<0.1)$.

Asphyxia was present in $15 \%$ of these children; $15.5 \%$ were born at sites with level I neonatal care, $18.6 \%$ were born at sites with level II neonatal care and $12.6 \%$ at sites with level III neonatal care. We find that asphyxiated versus nonasphyxiated kids have 2.86 (95\% confidence interval, 1.57-5.21) the unadjusted odds of developing a CP nonambulatory status, whereas linear probability model suggests that presence of perinatal asphyxia increases the probability of nonambulatory status by $27 \%$ all else being equal. Preterm birth is found to increase the chances of later

\section{Table 1: General characteristics of the population}

\begin{tabular}{|c|c|}
\hline Variables & $\mathrm{n}=\mathbf{3 6 0}$ children with $\mathrm{CP}$ \\
\hline \multicolumn{2}{|l|}{ Level of service at delivery } \\
\hline $\mathrm{I}, \mathrm{n}(\%)$ & $123(34.2)$ \\
\hline II, n (\%) & $70(19.4)$ \\
\hline III, n (\%) & $167(46.4)$ \\
\hline \multicolumn{2}{|l|}{ GMFCS level, N (\%) } \\
\hline Level I & $173(48.1 \%)$ \\
\hline Level II & $43(11.9 \%)$ \\
\hline Level III & $46(12.8 \%)$ \\
\hline Level IV & $50(13.4 \%)$ \\
\hline Level V & $48(12.3 \%)$ \\
\hline Maternal age, mean \pm SD & $29.64 \pm 5.05$ \\
\hline \multicolumn{2}{|l|}{ Mother's ethnic group } \\
\hline Caucasian & $292(81.11)$ \\
\hline Other & $68(18.89)$ \\
\hline \multicolumn{2}{|l|}{ Education } \\
\hline High school or more education & $319(88.6)$ \\
\hline Less than high school education & $41(11.4)$ \\
\hline Family history of CP, n (\%) & $17(4.72)$ \\
\hline History of stillbirths, n (\%) & $27(7.50)$ \\
\hline \multicolumn{2}{|l|}{ Type of pregnancy } \\
\hline Single fetus & $319(88.61)$ \\
\hline Preeclampsia, n (\%) & $27(7.50)$ \\
\hline Gestational diabetes, $\mathrm{n}(\%)$ & $52(14.44)$ \\
\hline Bleeding during pregnancy, $\mathrm{n}(\%)$ & $98(27.22)$ \\
\hline Severe illness during pregnancy, n (\%) & $78(21.67)$ \\
\hline Accident or trauma during pregnancy, n (\%) & $58(16.11)$ \\
\hline Birth weight $(\mathrm{g})$, mean $\pm \mathrm{SD}$ & $2594.78 \pm 1039.17$ \\
\hline Gestational age (weeks), mean \pm SD & $35.5 \pm 0.27$ \\
\hline Prematurity (<37 weeks), n (\%) & $151(41.94)$ \\
\hline Perinatal asphyxia, n (\%) & $53(14.72)$ \\
\hline
\end{tabular}

$\mathrm{CP}=$ cerebral palsy GMFCS $=$ Gross Motor Function Classification System; $\mathrm{SD}=$ standard deviation.

CP nonambulatory status by $9 \%$ all else equal, and low maternal education increased the risk of CP nonambulatory status by $2 \%$.

\section{DisCUSSION}

In Quebec, maternity care is regionalized, and nearly all deliveries take place in public hospitals. Low-risk deliveries are carried out at level I hospitals including birthing centers, whereas medium- and high-risk deliveries are referred to levels II or III hospitals. Prediction of the infant's state at birth determines referrals to level I, II, or III hospitals. High-risk deliveries are identified based on unified national medical guidelines. ${ }^{15,16,18}$ Our study demonstrated that the majority of children developing $\mathrm{CP}$ for perinatal reasons were born in birth sites with level III neonatal care. It reflects that, despite the current high level of 
Table 2: Propensity score matching results

\begin{tabular}{l|c|c|c|c}
\hline & & & LLR & LLR \\
\hline Levels & Radius: caliper $=\mathbf{0 . 1}$ & Kernel & EpanK & NormalK \\
\hline II vs I & -0.104 & -0.081 & -0.085 & -0.082 \\
\hline & $(0.071)$ & $(0.070)$ & $(0.217)$ & 0.154 \\
\hline III vs II & $0.163^{* *}$ & $0.157^{* *}$ & $(0.104)$ & $0.145^{* *}$ \\
\hline & $(0.063)$ & $(0.066)$ & -0.024 & $(0.071)$ \\
\hline III vs I & -0.054 & -0.072 & $(1.238)$ & -0.086 \\
\hline & $(0.069)$ & $(0.078)$ & $(0.076)$ \\
\hline
\end{tabular}

Propensity score estimates measure risk-adjusted change in the probability of non-ambulatory CP status resulting from increased level of service at delivery. Bootstrapped standard errors in parentheses (300 repetitions).

EpanK = Epanechnikov kernel; LLR = local linear regression; NormalK = Gaussian kernel.

\section{Table 3: Linear probability model results}

\begin{tabular}{|c|c|}
\hline Variables & Linear regression \\
\hline \multirow[t]{2}{*}{ Level II } & -0.072 \\
\hline & $(0.063)$ \\
\hline \multirow[t]{2}{*}{ Level III } & -0.012 \\
\hline & $(0.057)$ \\
\hline \multirow[t]{2}{*}{ Perinatal asphyxia } & $0.274 * * *$ \\
\hline & $(0.076)$ \\
\hline \multirow[t]{2}{*}{ Preeclampsia } & 0.030 \\
\hline & $(0.073)$ \\
\hline \multirow[t]{2}{*}{ Gestational diabetes } & -0.031 \\
\hline & $(0.067)$ \\
\hline \multirow[t]{2}{*}{ Bleeding during pregnancy } & -0.033 \\
\hline & $(0.054)$ \\
\hline \multirow[t]{2}{*}{ Severe illness during pregnancy } & -0.037 \\
\hline & $(0.054)$ \\
\hline \multirow[t]{2}{*}{ Accident/trauma during pregnancy } & 0.017 \\
\hline & $(0.057)$ \\
\hline \multirow[t]{2}{*}{ Preterm birth } & $0.092 *$ \\
\hline & $(0.05)$ \\
\hline \multirow[t]{2}{*}{ Family history of cerebral palsy } & 0.041 \\
\hline & $(0.089)$ \\
\hline \multirow[t]{2}{*}{ Maternal education } & $-0.024 *$ \\
\hline & $(0.013)$ \\
\hline \multirow[t]{2}{*}{ Maternal age } & 0.003 \\
\hline & $(0.005)$ \\
\hline \multirow[t]{2}{*}{ Drugs } & 0.061 \\
\hline & $(0.113)$ \\
\hline Observations & 358 \\
\hline
\end{tabular}

Level I hospitals are the base category. Robust standard errors are in parentheses. Statistical power $=0.76$. A $10 \%$ significance level is chosen because there is very little knowledge and no firm belief regarding the null hypothesis based on past experience. technology and obstetric and neonatal competences, outcome of the high-risk deliveries, referred to birth sites with level III neonatal care, still leads to significant long-term complications. Interestingly, $34 \%$ of children developing CP for perinatal reasons were born in sites with level I neonatal care.

We have shown that the differences in the level of neonatal care at the time of delivery did not seem associated with the risk of CP nonambulatory status. Our finding is consistent and robust across methods and empirical specifications used. Propensity score matching models suggested no effect relationship between the level of neonatal care available at hospital where delivery was carried out and risk of CP nonambulatory status between level II versus level I, level III versus level I comparisons. Positive coefficients were evident across the level III versus level II comparison, suggesting level II centers as protective; however, this might be reflective of the propensity score method inability to eliminate selection effects or unobserved heterogeneity between the two groups of hospitals. Instrumental variables estimation allowed us to control for possible selection effects and consistently found no relationship between the level of neonatal care at hospital where delivery was carried out and $\mathrm{CP}$ non-ambulatory status. To our knowledge, this is the first study where case mix adjustment was used to study the effects of perinatal regionalization on long-term outcomes and using instrumental variables methods.

The lack of impact of the level of neonatal care at the time of delivery on the risk of $\mathrm{CP}$ nonambulatory status is probably demonstrating the benefit of the development and generalization of the neonatal resuscitation program. The neonatal resuscitation program is for North American health care providers working in the delivery room and nurseries and is designed to aid in learning the cognitive and technical skills required for resuscitation of the newborn born babies and referral to specialized centers as soon as possible. ${ }^{19,20}$ Neonatal resuscitation was shown to reduce mortality from intrapartum-related events, ${ }^{21-23}$ such as perinatal asphyxia, and might explain no effect relationship found in our study. However, the lack of relationship between CP nonambulatory status and level of service at delivery might be due to the fact that within Quebec regionalized maternity service highrisk deliveries are identified in advance and are subsequently referred to hospital with appropriate level of service. This finding is consistent with exiting evidence that a regionalized maternity 
service within a publically owned and financed health system does not lead to increased infant morbidity. ${ }^{24}$

Perinatal asphyxia was highlighted as a significant risk factor for CP nonambulatory status because asphyxiated versus nonasphyxiated kids have 2.86 the odds of developing a $\mathrm{CP}$ nonambulatory status. In our cohort, the proportion of children with perinatal asphyxia born in each of the three neonatal care levels were approximately equal, being $15.5 \%, 18.6 \%$, and $12.6 \%$ in levels I, II, and III, respectively. However, nonambulatory status was more unevenly distributed and was present in $28.5 \%$ of kids born in level I, $20.0 \%$ of kids born in level II, and $29.3 \%$ of kids born in deliveries with level III. Perinatal asphyxia cannot be predicted before birth and thus has to be managed acutely in hospitals with different levels of technology and obstetric and neonatal competences available for neonatal care. Type of therapy the child receives immediately after birth is an important determinant of later $\mathrm{CP}$ severity. Newborns with perinatal asphyxia born in level I hospitals are usually transferred to level II or III hospitals, which have the capacity to provide an increased level of further care such therapeutic hypothermia. It is important to note that therapeutic hypothermia became widely available in Quebec as of 2009, so the birth cohorts included in this study did not have this therapeutic option. Lack of recognition of the patients that could benefit from this treatment remains a challenge, however, because there is a narrow window of opportunity to act. Because the proportion of births complicated by perinatal asphyxia among children with CP was evenly distributed among levels of neonatal care available at birth sites, it would be of interest to study the impact of lack of local availability of therapeutic hypothermia in level I centers on later risk of nonambulatory status. Our results also indicate that preterm birth and low maternal education may constitute important independent risk factors for CP nonambulatory status, which deserve further study.

Our study has several limitations. Methods used cannot replace a randomized controlled trial and thus might not be able to fully control for selection effects or unobserved covariates. However, a randomized controlled trial that would assess the impact of levels of neonatal care available at hospitals where delivery was carried out on $\mathrm{CP}$ ambulatory status is likely not to be undertaken given pragmatic concerns. Mortality is a competing outcome because it could potentially have reduced the number of CP nonambulatory cases. However, in our analysis, we observe mortality outcomes and we coded deaths as CP nonambulatory cases. Our rich data do not allow us to control for all possible postneonatal factors including the regional variability of pediatric rehabilitation services We find that differences in the level of care at delivery are not associated with CP nonambulatory status; however, our study does not discusses differences in other measures that might be important as well for determination of outcomes of regionalized perinatal care such as fine motor skills, cognition, language, or behavior.

In conclusion, our study implies that a regionalized maternity service does not affect the distribution of $\mathrm{CP}$ nonambulatory cases. This suggests that level of care and associated medical technology within the Quebec regionalized neonatal-perinatal system, is used efficiently because it does not offer any further marginal benefit in the reduction of severe $\mathrm{CP}$ outcomes. The system works well as it is and this is supportive of the perinatal regionalization. The success of the neonatal resuscitation program and referral of high-risk births to regional hospitals with sufficient obstetric and perinatal competence and resources may contribute to this lack of variability. Further research is needed to understand the causal links and associated mechanisms between prenatal risk factors, perinatal asphyxia, and CP severity.

\section{DisClosures}

Pia Wintermark has no disclosures relevant to this article. Michael Shevell and Maryam Oskoui have received research funding from NeuroDevNet for work in cerebral palsy. Maryam Oskoui has received research funding from CIHR for work in cerebral palsy. Corneliu Bolbocean received funding from NeuroDevNet Doctoral Fellow and Open Society Foundations GSGP Grant.

\section{SUPPLEMENTARY MATERIAL}

To view supplementary material for this article, please visit http://dx.doi.org/10.1017/cjn.2015.322

\section{REFERENCES}

1. Bode MM, O'shea TM, Metzguer KR, Stiles AD. Perinatal regionalization and neonatal mortality in North Carolina, 1968-1994. Am J Obstet Gynecol. 2001;184:1302-7.

2. Clement MS. Perinatal care in Arizona 1950-2002: a study of the positive impact of technology, regionalization and the Arizona perinatal trust. J Perinatol. 2005;25:503-8.

3. Toward improving the outcome of pregnancy: recommendations for the regional development of maternal and perinatal health services. White Plains, NY: March of Dimes National Foundation; 1976

4. Stark AR. Levels of neonatal care. Pediatrics. 2004;114:1341-7.

5. Levels of neonatal care. Pediatrics. 2012;130:587-97.

6. Lasswell SM, Barfield WD, Rochat RW, Blackmon L. Perinatal regionalization for very low-birth-weight and very preterm infants: a meta-analysis. JAMA. 2010;304:992-1000.

7. Kilpatrick SJ, Schlueter MA, Piecuch R, Leonard CH, Rogido M, Sola A. Outcome of infants born at 24-26 weeks' gestation: I. Survival and cost. Obstet Gynecol. 1997;90:803-8.

8. Bohin S, Draper ES, Field DJ. Impact of extremely immature infants on neonatal services. Arch Dis Child Fetal Neonatal Ed. 1996;74:F110-3.

9. Sinclair JC. Effectiveness of intensive care of very low birth-weight infants. Mead Johnson Symp Perinat Dev Med. 1982:23-8.

10. Cifuentes J, Bronstein J, Phibbs CS, Phibbs RH, Schmitt SK, Carlo WA. Mortality in low birth weight infants according to level of neonatal care at hospital of birth. Pediatrics. 2002;109:745-51.

11. Oskoui M, Joseph L, Dagenais L, Shevell M. Prevalence of cerebral palsy in Quebec: alternative approaches. Neuroepidemiology. 2013;40:264-8.

12. Rosenbaum P, Paneth N, Leviton A, Goldstein M, Bax M, Damiano D, et al. A report: the definition and classification of cerebral palsy April 2006. Dev Med Child Neurol Suppl. 2007;109:8-14.

13. Palisano R, Rosenbaum P, Walter S, Russell D, Wood E, Galuppi B. Development and reliability of a system to classify gross motor function in children with cerebral palsy. Dev Med Child Neurol. 1997;39:214-23.

14. Shi L. Health services research methods, 2nd ed.. Clifton Park, NY: Thomson; 2008.

15. Attendance at Labour and Delivery Guidelines for Obstetrical Care [Internet]. 2000. Available from: http://sogc.org/wp-content/ uploads/2013/01/89E-PS-May2000.pdf.

16. Liston R, Sawchuck D, Young D. Fetal health surveillance: antepartum and intrapartum consensus guideline. J Obstet Gynaecol Can. 2007;29(9 Suppl 4):S3-56.

17. Trønnes H, Wilcox AJ, Lie RT, Markestad T, Moster D. Risk of cerebral palsy in relation to pregnancy disorders and preterm birth: a national cohort study. Dev Med Child Neurol. 2014;56:779-85.

18. Gilbert NL, Fell DB, Joseph KS, Liu S, León JA, Sauve R. Temporal trends in sudden infant death syndrome in Canada from 1991 to 2005: contribution of changes in cause of death assignment practices and in maternal and infant characteristics. Paediatr Perinat Epidemiol. 2012;26(2):124-30. 
19. Public Health Agency of Canada. Family-centred maternity and newborn care: national guidelines. 2000. Ottawa, Canada.

20. Kattwinkel J. Textbook of neonatal resuscitation, 5th ed. Elk Grove Village, IL: American Academy of Pediatrics Association and American Heart Association; 2006.

21. Bang AT, Bang RA, Baitule SB, Reddy HM, Deshmukh MD. Management of birth asphyxia in home deliveries in rural Gadchiroli: the effect of two types of birth attendants and of resuscitating with mouth-to-mouth, tube-mask or bag-mask. J Perinatol. 2005;25(Suppl 1):S82-91.

22. Gill CJ, Phiri-Mazala G, Guerina NG, Kasimba J, Mulenga C, MacLeod WB, et al. Effect of training traditional birth attendants on neonatal mortality (Lufwanyama Neonatal Survival Project): randomised controlled study. BMJ. 2011;342:d346.

23. Lee ACC, Cousens S, Wall SN, Niermeyer S, Darmstadt GL, Carlo WA, et al. Neonatal resuscitation and immediate newborn assessment and stimulation for the prevention of neonatal deaths: a systematic review, meta-analysis and Delphi estimation of mortality effect. BMC Public Health. 2011; 11(Suppl 3):S12.

24. Grytten J, Monkerud L, Skau I, Sørensen R. Regionalization and local hospital closure in Norwegian maternity care-the effect on neonatal and infant mortality. Health Serv Res. 2014;49:1184-204. 